\title{
Nursing concerns with palliative care and at the end-of-life in patients with heart failure
}

\author{
This article was published in the following Dove Press journal: \\ Nursing: Research and Reviews \\ I2 February 20I5 \\ Number of times this article has been viewed
}

\author{
Cheryl Westlake' \\ Valerie Joy Smith ${ }^{2}$ \\ 'School of Nursing, Azusa Pacific \\ University, Azusa, CA, USA; \\ ${ }^{2}$ Department of Nursing, Keck Medical \\ Center of University of Southern \\ California, Los Angeles, CA, USA
}

Correspondence: Cheryl Westlake School of Nursing, Azusa Pacific University, West Campus, Building I, Office Room 3I I, 720 East Foothill Boulevard, Azusa, CA 91702, USA $\mathrm{Tel}+\mathrm{I} 6268156000 \times 5587$

Fax +16268155414

Email ccanary@apu.edu
Abstract: Patients with chronic heart failure (HF) suffer from numerous symptoms and quality-of-life (QOL) concerns, and thus, palliative care, a multidisciplinary approach that includes the family and focuses on the improvement of patients' and their families' QOL through the relief of physical, psychosocial, and spiritual suffering, is needed. The transition to hospice care is made when HF is refractory to medical therapy or when the potential harm of treatment outweighs the potential benefits. Nurses are key persons for patients with HF as they may initiate and support palliative and hospice care, focus on delivering patients' goal-directed, well-coordinated care, champion patients' and caregivers' needs, and facilitate optimal QOL. Despite the inclusion of palliative and hospice care for HF patients in published guidelines, health care providers are frequently unfamiliar with palliative and hospice care and the needs of HF patients and their families. Therefore, this paper addresses the nurses' role in determining for whom, and when palliative and hospice care is appropriate; where and how palliative and hospice care should be provided; and the communication needs of patients and their families regarding referral to hospice, emergencies, implantable cardioverter-defibrillator therapy, ventricular assist devices, and continuous intravenous inotropic or vasoactive support at the end-of-life.

Keywords: palliative care, hospice care, end of life care, palliative care nursing, hospice care nursing, heart failure, heart failure therapy

\section{Introduction}

Patients with chronic heart failure (HF) suffer from quality-of-life (QOL) concerns and numerous symptoms, and, thus, are in need of a palliative care (PC) approach early and throughout the disease trajectory and hospice care (HC) at the end-of-life (EOL). ${ }^{1-10}$ However, despite the inclusion of PC and HC for HF patients in published guidelines, ${ }^{11-13}$ physicians ${ }^{12}$ and nurses ${ }^{13}$ are frequently unfamiliar with the care and needs of HF patients. Therefore, the purpose of this article is to:

1. address the PC through HC continuum and for whom, when, and where PC and $\mathrm{HC}$ is appropriate;

2. describe critical components of PC and $\mathrm{HC}$; and

3. discuss the communication and decision-making needs of patients and their families during $\mathrm{PC}$ and $\mathrm{HC}$.

PC is a multidisciplinary, patient-centered approach that includes the family and may be provided in any care setting. Care focuses on the improvement of patients' and families' QOL through symptom prevention and management; the relief of physical, psychosocial, and spiritual suffering; and the provision of a support system, for 
patients until death and for grieving family members after the patients' death. ${ }^{4,14} \mathrm{HC}$ is EOL care when patients' $\mathrm{HF}$ is refractory to life-prolonging medical therapy and the patient has a prognosis of 6 months or less. Life-prolonging care is discontinued, and the care focus is now on preparation of the patient and family for death.

\section{Care coordination}

Patients and families require care that is highly coordinated and patient and family centric to optimize and integrate the most appropriate service delivery ${ }^{15}$ across all care settings. ${ }^{16}$ Organized and coordinated service planning and care delivery should include:

1. educating staff as to their role in the coordination of services;

2. ensuring adequate staff to support coordination activities;

3. facilitating timely communication across service providers through an interoperable information technology platform; and

4. supporting patient and caregivers with effective communication that understands and works well with and for them. ${ }^{17}$

As HF patients rarely thought about HF as a terminal illness failure ${ }^{18}$ and $68 \%$ of patients' spouses $(n=38)$ could not provide a definition of $\mathrm{PC},{ }^{19}$ they may need education about the aims and benefits of PC. High-quality PC, when introduced early, can promote a better understanding of the disease and illness trajectory, thus enabling patients to make more informed decisions with their families prior to the EOL. ${ }^{20}$ By championing patients' needs, clinicians can ensure that there is clear communication and improve the multidisciplinary team's collaboration to provide wellcoordinated, patient-focused care. ${ }^{21}$

\section{Critical components of PC}

Critical components of effective HF PC include care that is an integrated complement to life-prolonging HF care ${ }^{10,22}$ with a key health care provider coordinating the care; holistic and regular assessment, and monitoring; ${ }^{23}$ patientcentered, goal-defined ${ }^{20}$ care plans that include planning for the future, ${ }^{10,22}$ and an advanced directive that is reviewed regularly by the care team, patient, and caregivers. Care must be coordinated across care settings. ${ }^{1}$ Regular assessment and review of the caregivers' needs and caregiver support ${ }^{10,22}$ that includes respite and bereavement care are also important. ${ }^{24}$

\section{Care planning}

From the time of diagnosis, goals of care and care preferences must be discussed and established with the patient and family. Planning should take place before the patient becomes too incapacitated to participate in decision-making and consider such issues as how to respond to sudden HF exacerbations, progression of comorbid conditions, and cardiac arrest. ${ }^{22,25}$ If patients prefer not to participate in decision-making, then they should be asked to appoint someone to make decisions on their behalf, and the process, decision, and details regarding the appointee should be documented. The care plans must be reviewed regularly, especially during periods of significant clinical change (hospitalization, additional comorbidities, disease progression). ${ }^{16,25,26}$

Care preferences are related to knowledge and understanding deficits, ${ }^{17,27}$ health-literacy, ${ }^{28}$ educational level, ${ }^{22}$ time constraints, ${ }^{26,27}$ and difficulties in navigating and accessing health and social care support. ${ }^{17,22,27}$ Given that care preferences are rarely discussed on hospital admission, ${ }^{3}$ clinicians must engage patients in conversations about what will happen during and following the hospital admission. In general, patients want more information than is provided to them by clinicians about their disease. ${ }^{29}$ As the majority of older HF patients demonstrate poor health-literacy, especially with respect to $\mathrm{HF},{ }^{30}$ attention is needed to provide low health-literacy appropriate teaching, decision-making, and care. Further, attention to ameliorating the time constraints and navigation difficulties is needed.

\section{Advance directives}

Advance directives are legal documents created by patients and shared with the family and clinicians that identify desired or undesired treatments in the event an individual becomes incapacitated and incapable of making or communicating decisions about care preferences. The individual identified by the patient to serve as their spokesperson is documented. Thus, patients are assured that their health-care team knows their care preferences and spokesperson.

Disease Specific Advance Care Planning, a facilitated advanced planning intervention that emphasized conditionspecific treatment, resulted in greater understanding of patient goals and higher rates of advance directives completion for those who participated in the intervention versus those who did not $(94.3 \%$ versus $24.8 \%$; $P<0.001)$. Of patients who died by the end of the study period $(n=286,15 \%)$, intervention participants were more 
likely to have used hospice than control participants $(56 \%$ versus $37 \%$; $P=0.002) .{ }^{17}$

During discussions about care preferences, prognosis, resuscitation (cardiopulmonary resuscitation [CPR], advanced life support), and circumstances for discontinuing invasive therapy such as inotropic infusions or cardiac devices (cardiac resynchronization, ventricular assist) should be carefully and objectively explored with both patients and families. ${ }^{14,22,31}$ Unfortunately, only $43 \%$ of patients report that their physician discussed their care preferences with them. ${ }^{32}$

\section{Resuscitation}

Discussions about resuscitation care preferences are important to ensure patient-centered care. In patients with severe HF, $8 \%$ were unsure about resuscitation, $23 \%$ preferred no resuscitation, and $19 \%$ changed their preference after 6 months. However, during the last month of life in patients older than 80 years who died within 1 year of their enrollment hospitalization, $60 \%$ in hospital and $80 \%$ out of hospital preferred not to be resuscitated. At the time of death, $80 \%$ of these elderly patients had a "do not resuscitate" order and $60 \%$ had an order to withhold a ventilator. ${ }^{33}$ Therefore, clinicians must discuss and document the patients' wishes for resuscitation initially and periodically throughout the patients' care.

\section{Cardiac resynchronization therapy}

Patients receiving cardiac resynchronization therapy require discussions about care preferences for deactivation of the implantable cardioverter-defibrillator (ICD) in the event they develop end-stage disease. As part of the discussion, clinicians need to ensure that patients and families understand that turning off the ICD means that the device will no longer provide lifesaving intervention if a fatal heart rhythm occurs and that immediate death and pain will not be caused. . $^{14,34}$

In the largest American study looking at 105 symptomatic HF patients receiving cardiac resynchronization therapy and their ICD care preferences, recipients of ICDs (66\%) were more confident about the device's lifesaving capacity than patients who did not have one. ${ }^{35}$ Not surprisingly then, patients with ICDs were hesitant to have their devices deactivated if they developed end-stage disease. Also, patients preferred the ICD to remain active even if they were dying of cancer $(70 \%)$ or having daily shocks $(55 \%)$, and none of them inactivated the ICD if suffering from dyspnea at rest. ${ }^{35}$
Clinicians infrequently discuss ICD deactivation with patients and most devices remain active, continuing to shock until death. ${ }^{14,30,36}$ The concurrent Working to Improve diScussions about DefibrillatOr Management, a six-center trial, reports $27 \%$ of patients received shocks at the EOL with the experience being painful, traumatic, and distressing for patients and families. ${ }^{37}$ Therefore, particular care should be taken to ensure that discussions of ICD deactivation occur early, with the patient and family together while the patient is still capable of participating.

\section{Ventricular assist devices}

Care preferences regarding ventricular assist devices (VADs) need to be addressed before implantation of the VAD and revisited with any significant change in the patients' status that changes the goals of support. ${ }^{38}$ Patients need to understand that the VAD may prolong the dying process and continue to work even after the patient is clinically brain dead. ${ }^{25,39}$ Thus, the establishment of the patients' advance directives and the documented discussions that outline the conditions under which the patients desire the device to be withdrawn is critical to ensure the patients' wishes are met. ${ }^{39-41}$

Discussions need to include PC and EOL care wishes relative to the VAD particularly for patients with VAD support for long periods of time or patients who are living with unpleasant symptoms caused by complications of VAD support. ${ }^{38}$ Of 20 patients with a VAD who actively participated in VAD care preference discussions, retrospective review showed that 17 chose to actively withdraw support and three chose to wait until they lost consciousness before having the device withdrawn. The time from the decision to withdraw the VAD was less than 1 day-2 weeks and from withdrawal to death was less than 20 minutes. Therefore, patients need to understand the immediacy of death following VAD withdrawal, queried about the conditions under which they would desire the device be withdrawn, and the VAD care preferences should be documented to ensure the patients' wishes are met. ${ }^{39-41}$

\section{Sudden cardiac death and resuscitation}

While the focus of advanced therapy is to optimize function and prolong life, the life-limiting nature of HF and increased risk of associated sudden cardiac death (SCD) should be acknowledged and discussed at the time of diagnosis as part of the initial education offered to HF patients and families. ${ }^{14,22}$ Patients with HF do not perceive 
the life-limiting nature of HF. ${ }^{18,42}$ Thus, patients and family members need explicit communication about the HF disease trajectory, the life-limiting nature of $\mathrm{HF},{ }^{13}$ the prognosis, and the possibility of SCD despite optimal care. ${ }^{43}$ Providing HF patients and families a warning that death may come abruptly or with chronic illness helps eliminate surprise from future communications when the patient's health condition suddenly deteriorates or he/she is at the EOL. ${ }^{44}$ In addition to helping them prepare for the worst should they die sooner than expected, knowledge of the life-limiting nature of HF may also assist patients and their families to better adhere to the PC treatment plan: medication, ${ }^{14,17,22}$ diet, ${ }^{14}$ and exercise. ${ }^{14,25}$

Communication should begin with the clinician asking patients about their understanding of HF, and determining the patient and family desired information. Then, the clinician provides small chunks of information, and seeks patient and family feedback to elicit understanding. ${ }^{45}$ The discussions need to be regular and repeated, particularly at times of change, to ensure understanding and patient/family satisfaction. ${ }^{46}$ Developing sensitive communication skills is an essential component for effective discussions of PC and EOL issues. ${ }^{26}$

All HF patients and their families should create a plan to manage potential SCD, including those with lifeprolonging interventions such as ICDs. ${ }^{22,45}$ Patients report wanting their families to know what to do in an emergency, and families commonly express the need to know how to respond in a cardiac emergency. Families report that the learning need about emergencies is often unmet by healthcare professionals..$^{46-48} \mathrm{~A}$ discussion involving patients and families about the patients' wishes regarding resuscitation can include information about the effectiveness of resuscitation and the associated sequelae. ${ }^{49}$ The majority of family members of patients at risk for SCD can successfully learn $\mathrm{CPR}$, are not burdened by responsibility or guilt, and utilize CPR techniques appropriately when the need arises..$^{50,51}$

For those patients who choose to allow for a natural death, their family caregivers need to be told what to do when death occurs outside the hospital. The caregivers should be instructed to contact a health-care provider who has a relationship with the patient not 911, inform the provider of the patient's preference to not attempt resuscitation, and discuss the need of the provider to certify the cause of death.

The importance of patients' trust in health professionals and their belief that they will receive good care through to death cannot be overstated. ${ }^{52}$ In addition, emotional and spiritual support that includes the assessment of family stresses and financial resources and the identification of coping strategies and roles ${ }^{22}$ needs to be provided to both the patient and caregivers. To provide optimal PC, clinicians need to be knowledgeable about the patients' and caregivers' needs regarding HF self-management.

\section{Clinicians' role in determining when and for whom PC and HC is appropriate}

PC needs to be considered and initiated at the time the patient is diagnosed with $\mathrm{HF}^{53} \mathrm{PC}$ needs to be incrementally increased as the HF progresses, until, eventually, life-prolonging care is discontinued and the transition to $\mathrm{HC}$ is made.

Generally, patients in New York Heart Association classes I-III HF are appropriate patients for whom PC may be offered. Thus, patients with mild HF (no/slight physical activity limitation) to patients with moderate HF (marked physical activity limitation [fatigue, palpitation, or dyspnea]) may be suitable for PC.

If $\mathrm{PC}$ is provided by a separate, distinct service, early consultation is recommended as PC consultations generally occur too late (median time from PC consultations to death is 21 days [3-125]). ${ }^{17}$ Timely PC consultations result in increased referrals to hospice, integration of broader PC services, ${ }^{17}$ and earlier referrals to $\mathrm{HC} .{ }^{54}$ Also, early consultation may reduce symptom burden and depression while enhancing QOL. ${ }^{55}$

\section{Key components of PC - QOL and symptom management}

For patients, living with HF involves many losses, changes, and challenges. ${ }^{56} \mathrm{HF}$ involves managing the illness (organizing medications and other care) and maintaining the illness (partitioning activities into manageable chunks plus strict timing and organization of activities). ${ }^{57}$ Patients experience significant fatigue, ${ }^{58}$ and difficulties with managing and maintaining daily activities that result in a need to rely on others. As a result, many experience a loss of activities (social gatherings/work) and an associated disruption of their self-image. The recognition that help from others is required to manage $\mathrm{HF}^{56}$ results in feelings of loneliness, isolation, and being a burden. ${ }^{52}$ Thus, helping patients to manage symptoms through ongoing education, interventions, and reevaluation; optimizing their social activities and feelings of self-worth through actual/virtual and in-/out-of-home events; and facilitating the infrastructure needed to live with HF through referrals to and consultations with auxiliary members of the health-care team ${ }^{57}$ are critical to optimizing QOL. However, 
additional data are needed to optimize QOL and symptom management. ${ }^{1}$

The content, structure, and timing of PC aimed at improving the QOL for both patients and families were addressed using in-depth interviews of 33 adult outpatients with symptomatic HF and 20 of their family caregivers. ${ }^{36}$ They described the needed content as symptoms alleviation and adjustment to limitations and the future illness course..$^{58}$ Patients and family caregivers said that services should be structured using a team approach by clinicians familiar with the patient and that family caregivers should be involved in the PC to enhance communication and coordinate care. PC services should begin at the beginning of illness and continue throughout the illness. ${ }^{59}$ Thus, clinical care in advanced HF needs to focus on improving communication, self-care, and advanced care planning, ${ }^{29,36,41,59}$ while considering the particular health beliefs, values, and coping mechanisms. ${ }^{26}$

\section{Relief from suffering Physical and psychosocial suffering}

Common symptoms associated with advanced HF and recommendations for symptom management are provided in Tables 1 and 2 .

In addition to physical symptoms, HF patients are frustrated by living with HF and describe the need to talk about the:

1. disease/symptoms, ${ }^{23,93}$

2. necessity to be on medication;

3. decisions regarding advanced directives and $\mathrm{HC}^{57}$ and

4. need for information and better communication from their health-care team..$^{23,93}$

Patients' emotional symptoms include hopelessness, ${ }^{94}$ sadness, and feeling imprisoned by their illness. ${ }^{93}$ Further, as comorbid depression is common in both patients and caregivers, assessment and treatment of depression is critical for both. ${ }^{10}$ Patients also fear pain, dying too young, and

Table I Common symptoms associated with advanced HF

\begin{tabular}{ll}
\hline Symptom class & Examples \\
\hline Physical & $\begin{array}{l}\text { Dyspnea, pain, edema, fatigue, exercise intolerance, } \\
\text { anorexia, nausea, constipation, gout, pruritus, pain, } \\
\text { muscle cramps }\end{array}$ \\
Panic attacks, fear, anxiety, depression, cognitive \\
impairment, loss of confidence, insomnia, feelings \\
of uselessness or hopelessness, feelings of social \\
isolation, feeling a burden \\
Falls, trouble walking, incontinence, loss of \\
independence in performing activities of daily living
\end{tabular}

Note: Data from. 1,13,14,22,30,43,47,57

Abbreviation: HF, heart failure. agreeing to a treatment they did not want at the end. Patients with HF need assistance to live with inadequate information, uncertainty, anxiety, psychological morbidity, and the inability to plan appropriately. ${ }^{9}$

Not being a burden to their family is extremely important to patients with HF (43.5\%), yet only $22 \%$ are completely satisfied that they are not a burden. ${ }^{95}$ As patients with HF fear being a burden as they deteriorate and become more dependent, ${ }^{93}$ attention to the fear, dependence, ${ }^{52}$ and personal and home adaptations is critical.

The Needs Assessment Tool: Progressive Disease-Heart Failure is an easy to administer, comprehensive, and relevant tool to objectively determine HF patient needs. ${ }^{96}$ Finally, HF patients' experience and needs-based discussions linked to patients' values must occur over time, ideally, and may require revisiting at turning points in the patients' disease trajectory. Understanding the experiences and needs of HF patients is critical to informing patient-centered $\mathrm{PC}$ as some patients have unmet PC needs. ${ }^{23}$

\section{Spiritual suffering}

Spiritual concerns are important for many patients, both early and late in the illness progression. The spiritual needs for patients with HF; the need for love, belonging, hope, coping, meaning, ${ }^{94}$ and purpose $;{ }^{96}$ and the need for attention to their faith, beliefs, existential issues,${ }^{97}$ and loneliness may exist whether or not they have religious beliefs. Unfortunately, only a minority of patients report that their physician discussed their religious beliefs (31\%). ${ }^{32}$ Importantly, clinicians must address the spiritual needs and concerns of patients.

Patients describe a three-step (past, present, and future oriented) process where spirituality contributed to their adjustment to advanced HF: 1) the development of regret regarding behaviors and lifestyles; 2) the search for meaning within the experience of HF; and 3) the search for hope and reclaiming of optimism. ${ }^{94}$ Patients' hope may be simply about the ability to go for a walk, get out of the house, or gain some independence while others hope for a longer life or time to participate in an important event, like a wedding or graduation. ${ }^{98}$ Hopelessness may be present alongside feelings of hope, but for some, hopelessness is a feeling that their lives are finished..$^{93}$ Thus, clinicians must work to facilitate patients' adjustment to HF by facilitating the resolution of their regret; their understanding about the meaning and purpose for their life, and the search for hope; and the reclaiming of optimism.

The balancing of hopes and fears is common to PC and HC. ${ }^{52}$ Patient-centered care with a focus on the patient as a 
Table 2 Symptom management in PC

\begin{tabular}{|c|c|}
\hline Physical symptoms & Treatment \\
\hline \multirow[t]{3}{*}{ Poor 6-minute walk distance } & Angiotensin-converting enzyme inhibitors ${ }^{60}$ \\
\hline & Angiotensin-converting enzyme inhibitors in patients with NYHA functional classes II-III HF ${ }^{6 I}$ \\
\hline & Caffeine ${ }^{62}$ \\
\hline \multirow[t]{14}{*}{ Exercise intolerance, exertion, fatigue } & Angiotensin-converting enzyme inhibitors ${ }^{61,63}$ \\
\hline & Continuous positive airway pressure ${ }^{64}$ \\
\hline & Loop diuretics ${ }^{65}$ \\
\hline & Fluid and sodium intake restriction ${ }^{66}$ \\
\hline & Caffeine ${ }^{62}$ \\
\hline & Treatment of secondary causes such as anemia (with erythropoietin ${ }^{73}$ ), infection, sleep apnea, ${ }^{98,143}$ \\
\hline & or depression 22 \\
\hline & Enhance self-assessed control over their $\mathrm{HF}^{67}$ \\
\hline & Exercise $^{68,69,144}$ \\
\hline & Inspiratory respiratory muscle training ${ }^{70-72}$ \\
\hline & Stimulants ${ }^{143}$ \\
\hline & Hawthorne extract ${ }^{137}$ \\
\hline & Cardiac resynchronization therapy ${ }^{74}$ \\
\hline & Destination left ventricular assist devices ${ }^{75}$ \\
\hline Muscle weakness & Specific thigh muscle training ${ }^{76}$ \\
\hline \multirow[t]{15}{*}{ Dyspnea/orthopnea/edema } & Angiotensin-converting enzyme inhibitors in patients with NYHA functional classes II-III HF ${ }^{6 I}$ \\
\hline & Aldosterone blockade with monitoring of patient-reported symptoms to assess individual benefit ${ }^{77}$ \\
\hline & Loop diuretics ${ }^{65}$ with or without thiazides ${ }^{129}$ in patients with LVSD ${ }^{78}$ \\
\hline & Aquapheresis (if diuretic resistant) $)^{133}$ \\
\hline & Nitrates ${ }^{120}$ or low-dose opioids ${ }^{25,130,131}$ \\
\hline & Opioids in NYHA functional classes II-III patients ${ }^{80-82}$ \\
\hline & Nitroglycerine, intravenous for decompensated $\mathrm{HF}^{79}$ \\
\hline & Inotropes ${ }^{132}$ \\
\hline & Fluid and sodium intake restriction ${ }^{66}$ \\
\hline & Breathing ${ }^{134}$ and inspiratory respiratory muscle training ${ }^{75-77}$ \\
\hline & Specific thigh muscle ${ }^{76}$ and exercise training ${ }^{135}$ \\
\hline & Walking aids ${ }^{134}$ \\
\hline & Hawthorn extract ${ }^{136}$ \\
\hline & Oxygen (without hypoxia) ${ }^{137}$ \\
\hline & Hand held fan ${ }^{150}$ \\
\hline \multirow[t]{7}{*}{ Poor QOL } & Beta-blockers ${ }^{83,84}$ \\
\hline & Nocturnal oxygen supplementation in HF patients with Cheynes-Stokes respiration ${ }^{85}$ \\
\hline & Loop diuretics in patients with LVSD ${ }^{78}$ \\
\hline & Exercise ${ }^{68,69}$ \\
\hline & Inotrope infusion therapy ${ }^{86,87}$ \\
\hline & Cardiac resynchronization therapy ${ }^{74}$ \\
\hline & Destination left ventricular assist devices ${ }^{75}$ \\
\hline \multirow[t]{2}{*}{ Cheynes-Stokes respiration } & Continuous positive airway pressure ${ }^{88}$ \\
\hline & Aerobic exercise ${ }^{89}$ \\
\hline \multirow[t]{7}{*}{ Intermittent pain } & Intermittent opioids (morphine, codeine [and possibly hydromorphone]) - only for intermittent use, ${ }^{79}$ \\
\hline & plus stimulant laxative prescription' \\
\hline & Nitrates, beta-blockers, calcium channel blockers, ranolazine, and coronary revascularization for anginal \\
\hline & 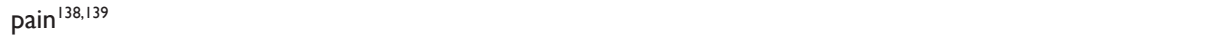 \\
\hline & Acupuncture ${ }^{140}$ \\
\hline & Exercise training ${ }^{|4|}$ \\
\hline & Music $^{142}$ \\
\hline \multirow{5}{*}{$\begin{array}{l}\text { Osteoarthritis or chronic } \\
\text { musculoskeletal pain }\end{array}$} & Combination of muscle-strengthening exercises, assistive devices/modalities (heat, cold, ultrasound), intra- \\
\hline & articular joint injection, and around-the-clock \\
\hline & Intermittent opioids (morphine, codeine [and possibly hydromorphone]) - only for intermittent use, ${ }^{79}$ \\
\hline & plus stimulant laxative prescription' \\
\hline & Opioids and bisphosphonates for bone pain I ${ }^{38}$ \\
\hline
\end{tabular}


Table 2 (Continued)

\begin{tabular}{|c|c|}
\hline $\begin{array}{l}\text { Psychological/social/functional } \\
\text { symptoms }\end{array}$ & Treatment \\
\hline \multirow[t]{2}{*}{ Emotional function, sense of control } & Continuous positive airway pressure ${ }^{64}$ \\
\hline & Enhance self-assessed control over their $\mathrm{HF}^{67}$ \\
\hline \multirow{3}{*}{ Anxiety } & Increase spousal sense of control90 \\
\hline & Mindfulness support group and HF education ${ }^{91}$ \\
\hline & Benzodiazepines' \\
\hline Social function and vitality & Continuous positive airway pressure ${ }^{64}$ \\
\hline \multirow[t]{5}{*}{ Depression } & Selective serotonin reuptake inhibitors - in patients with renal impairment monitor serum sodium ${ }^{92}$ \\
\hline & Serotonin-norepinephrine reuptake inhibitors and tricyclic antidepressants ${ }^{145}$ \\
\hline & Psychological interventions such as cognitive behavioral therapy, counseling, or supportive therapy ${ }^{146}$ \\
\hline & Mindfulness support group and HF education ${ }^{91}$ \\
\hline & Exercise $^{147}$ \\
\hline
\end{tabular}

Abbreviations: PC, palliative care; NYHA, New York Heart Association; HF, heart failure; LVSD, left ventricular systolic dysfunction; QOL, quality-of-life.

whole person with emotional, social, and spiritual needs in addition to physical concerns and symptom management could demonstrate the holistic caring approach patients and families seek.

\section{Transition}

The transition to $\mathrm{HC}$ or EOL care is made when the patient wishes or when the potential harm of treatment outweighs the potential benefits. However, the transition from the independence of $\mathrm{PC}$ to the dependence of $\mathrm{HC}$ is not a simple linear process for patients with $\mathrm{HF}^{52}$ Identification of patients nearing the EOL should be made in collaboration with clinicians experienced in the care of patients with HF, when possible, and coordinated with the patients' primary care physician. ${ }^{32}$

\section{Hospice care}

Prognostication in HF is difficult. ${ }^{1}$ Guidelines for HF care do not specifically address when to refer end-stage HF patients for $\mathrm{HC}$ or EOL care, ${ }^{99}$ and the National Hospice Organization prognostic criteria for determining hospice eligibility in $\mathrm{HF}$ patients are not useful in predicting 6-month prognosis. ${ }^{100}$ Further, the HF trajectory is unpredictable with varying periods of remission and exacerbation, ${ }^{101,102}$ and there is no typical trajectory. ${ }^{103}$ Thus, when to refer patients to $\mathrm{HC}$ may be difficult to determine. Generally, however, patients in stage D/New York Heart Association class IV HF and patients with severe HF who are unable to do any physical activity without discomfort and/or experience symptoms at rest may be considered for HC. In a small study of 282 patients older than 70 years (mean age 79 years), 43 patients died within 6 months of study enrollment and were assessed for common clinical characteristics.

Serum blood urea nitrogen $\geq 30 \mathrm{mg} / \mathrm{dL}$ (odds ratio $[\mathrm{OR}]=5.78,95 \%$ confidence interval $[\mathrm{CI}]=2.65-12.66$ ), systolic blood pressure $<120 \mathrm{mmHg}$ (OR $=4.81$, $95 \% \mathrm{CI}=1.94-11.91)$, peripheral arterial disease $(\mathrm{OR}=3.09$, $95 \% \mathrm{CI}=1.26-7.58)$, and serum sodium $<135 \mathrm{mEq} / \mathrm{L}$ $(\mathrm{OR}=2.27,95 \% \mathrm{CI}=0.98-5.27)$ were independent clinical correlates of 6-month mortality. ${ }^{104}$ Thus, patients with these four clinical characteristics may represent HF patients for whom referral $\mathrm{HC}$ might be appropriate.

\section{Prognosis/mortality}

Breathlessness was the most common symptom (men $90 \%$, women $86 \%$ ) of 21 symptoms documented in the charts of late-stage HF patients ${ }^{13}$ while in the last 6 months of life, the two symptoms most commonly reported by family members were dyspnea (61\%) and pain (78\%). ${ }^{43,105}$ In addition, low mood was reported by $59 \%$, sleeplessness by $45 \%$, anorexia by $43 \%$, and confusion by $40 \%{ }^{43}$ The significant predictors for $\mathrm{HC}$ and in-hospital mortality are provided in Table 3.

Single-item predictors such as the 6-minute walk test, ${ }^{109}$ B-type natriuretic peptide, ${ }^{110}$ and creatinine levels ${ }^{111}$ may be clinically helpful. Prognostic factors, tools, and models developed for HF may be useful too. Ongoing assessments of patients at high likelihood of death at 1 year may be assessed by using a prognostic, multivariable model (HF Survival Score, ${ }^{112}$ Zugck two-variable model, ${ }^{113}$ HF Risk Scoring System, ${ }^{114} \mathrm{HF}$ Risk Calculator, ${ }^{115}$ Digitalis Investigation Group model, ${ }^{116}$ Seattle HF model, ${ }^{117}$ Munich score, ${ }^{118}$ and the Barcelona Bio-HF Risk Calculator ${ }^{119}$ ). However, no reliable and validated tool is available to determine death within 6 months contributing to the difficulty of timely referrals (Table 4).

The HF Risk Scoring System ${ }^{14}$ is a 30 -day mortality risk predictor and the Palliative Performance Scale, a generic tool that assesses ambulation, activity and extent of disease, self-care, intake, and consciousness level, ${ }^{120}$ 
Table 3 Predictors of need for hospice care and in-hospital mortality

\begin{tabular}{|c|c|c|}
\hline Predictors & Need for $\mathrm{HC}^{14,106}$ & In-hospital mortality ${ }^{107,108}$ \\
\hline Age: $>70$ years; per 10 -year increase & & $\mathrm{x}$ \\
\hline African American & & $x$ \\
\hline Heart rate: per $10 \mathrm{bpm}$ increase between $65 \mathrm{bpm}$ and $110 \mathrm{bpm}$ & & $\mathrm{x}$ \\
\hline Systolic blood pressure: $\leq 124 \mathrm{mmHg}$; per $10-\mathrm{mmHg}$ increase up to $160 \mathrm{mmHg}$ & & $\mathrm{x}$ \\
\hline Diastolic blood pressure: per $10-\mathrm{mmHg}$ increase up to $100 \mathrm{mmHg}$ & & $\mathrm{x}$ \\
\hline Presence of edema & $\mathrm{x}$ & \\
\hline General deterioration - orthopnea, nocturia, dyspnea & $x$ & \\
\hline Weight increases and fails to respond to increased diuretics & $\mathrm{x}$ & \\
\hline Sodium: per 3-mEq/L decrease, above or below $140 \mathrm{mEq}$ & & $\mathrm{x}$ \\
\hline Low sodium & $X<134 \mathrm{mEq} / \mathrm{L}$ & $X<136 \mathrm{mEq} / \mathrm{L}$ \\
\hline Serum creatinine: per $0.3-\mathrm{mg} / \mathrm{dL}$ increase up to $3.5 \mathrm{mg} / \mathrm{dL}$ & $X>2 \mathrm{mg} / \mathrm{dL}$ & $\mathrm{X}>1.4 \mathrm{mg} / \mathrm{dL}$ \\
\hline BUN: $>37 \mathrm{mg} / \mathrm{dL}$ & & $\mathrm{x}$ \\
\hline Low hemoglobin & & $\mathrm{x}$ \\
\hline Severe limitations, NYHA IV & $\mathrm{X}$ & \\
\hline Moderate disability requiring considerable assistance and frequent care (Karnofsky score $\leq 50 \%$ ) & $\mathrm{X}$ & \\
\hline$>3$ hospital admissions/year & $\mathrm{X}$ & \\
\hline$>3$ severe HF exacerbations/year & $\mathrm{X}$ & \\
\hline \multicolumn{3}{|l|}{ Pain } \\
\hline \multicolumn{3}{|l|}{ Ejection fraction improvement at 6 months } \\
\hline Low cardiac output & $x$ & \\
\hline Cause of admission: HF & & $\mathrm{X}$ \\
\hline ACE inhibitor or beta-blocker at admission & & $\mathrm{x}$ \\
\hline Patient mentions EOL approaching & $\mathrm{X}$ & \\
\hline Presence of cancer & & $\mathrm{x}$ \\
\hline Smoker within past year & & $\mathrm{X}$ \\
\hline $\begin{array}{l}\text { Hyperlipidemia, liver disease, chronic obstructive pulmonary disease, peripheral vascular } \\
\text { disease, left ventricular systolic dysfunction, or no known HF before current admission }\end{array}$ & & $\mathrm{X}$ \\
\hline Previous cerebrovascular accident/transient ischemic attack & $\mathrm{x}$ & $\mathrm{X}$ \\
\hline \multicolumn{3}{|l|}{ Diabetes mellitus } \\
\hline \multicolumn{3}{|l|}{ Chronic renal insufficiency } \\
\hline Low cutaneous flow & & \\
\hline
\end{tabular}

Abbreviations: HC, hospice care; BUN, blood urea nitrogen; NYHA, New York Heart Association; IV, intravenous; HF, heart failure; ACE, angiotensin-converting enzyme; EOL, end-of-life.

may predict risk of death within 1-145 days. Both were correlated with 1 year death prediction. ${ }^{121}$ However, nurses' prognostic predictions for hospitalized HF patients were better than either prognostic model. ${ }^{122} \mathrm{HC}$ may be provided in the home, a long-term care center, or a special hospice unit ${ }^{20}$ and is designed to provide symptom relief, comfort, and support for patients and their families. In a long-term care center, families communicated with many health-care providers, but most often worked through the nurse when problems arose or decisions about care needed to be made. ${ }^{123}$

Key components of quality $\mathrm{HC}$ include the provision of easy access to coordinated care, ${ }^{15}$ support for emotional and spiritual concerns, adequate pain and symptom management, and avoidance of the inappropriate prolongation of death. Patients' perceived sense of control and strengthened relationships with the loved ones are critical to optimal HC. ${ }^{46,94,124}$ Patients acknowledge endings and losses, the need to manage regrets about previous behavior and uncertainty, ${ }^{95}$ and the desire for good care at the EOL. ${ }^{53}$

Early referrals to $\mathrm{HC}$ are preferable to late referrals as late referrals are associated with lower overall family satisfaction, hospice services' satisfaction, and confidence in participating in patient care at home. Further, later referrals yield more unmet needs, a lack of awareness about what to expect at the time of death, and concerns about care coordination. ${ }^{125}$ In half of all cases of late referral, family members reported that physicians were a barrier to earlier hospice referral. ${ }^{102}$

\section{Implantable cardioverter devices}

The maintained activation of the ICD when transitioning to $\mathrm{HC}$ may be an issue. A survey of 414 hospices reported that only $20 \%$ of hospices assessed patients for the presence of an ICD on admission with only $10 \%$ of them having a deactivation policy. ${ }^{126}$ Of the patients with active devices, $42 \%$ had the shocking function turned off once they 


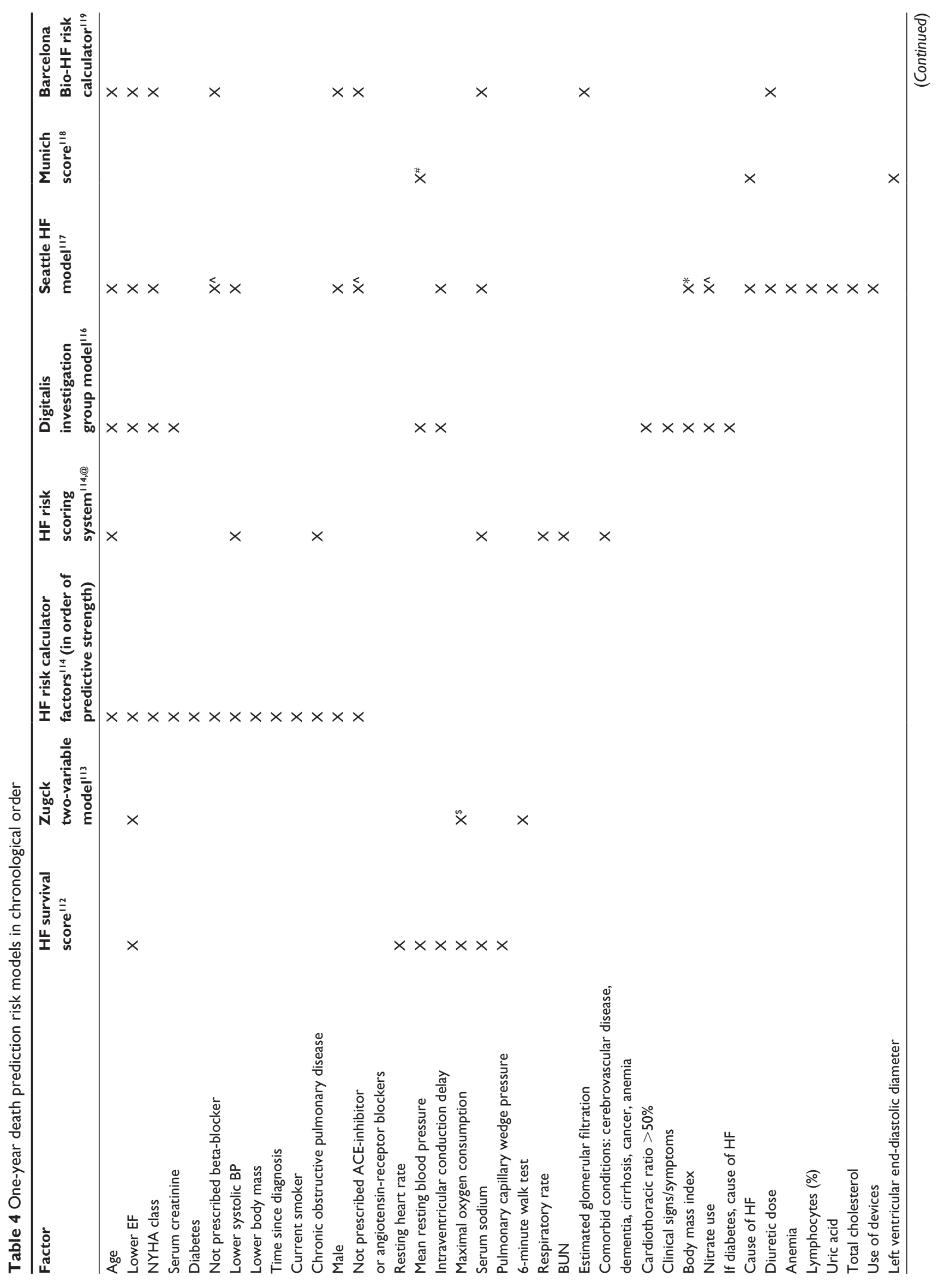




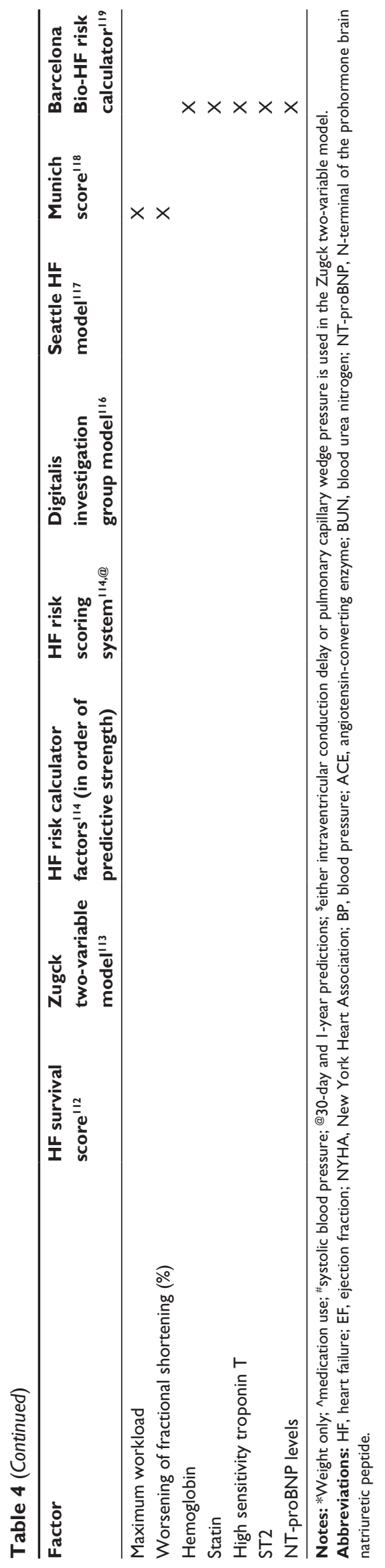

transitioned to HC. ${ }^{126}$ However, as patients were hesitant to have their devices deactivated if they developed endstage disease and none would inactivate the ICD if suffering from dyspnea at rest, ${ }^{35}$ consideration of hospice policies and patients' ICD care preferences need to be considered when referring patients to hospice.

\section{Preferences about death and dying}

As $\mathrm{HC}$ is focused on providing a good death, ${ }^{117}$ attention to how patients define a good death is warranted. ${ }^{127} \mathrm{HF}$ patients described the best death as a death that is peaceful and without panic. Further, the preference is for dying with dignity, dying without suffering, and dying in institutional settings for the majority of older participants. ${ }^{5,117}$

Although many patients were willing to talk about their feelings, a significant number expressed ambivalence or reservation about answering questions related to death. ${ }^{56}$ Some patients were disappointed that the health-care team did not discuss dying with them ${ }^{95}$ while some older HF patients did not want an open acknowledgment of the imminence of dying and death. ${ }^{117}$ In addition, as only $25 \%$ of patients had discussed their preference with their provider, ${ }^{117}$ it is incumbent upon clinicians to initiate the discussion about the patients' definition of a good death and their treatment preferences including $\mathrm{HC}$, to document the findings, and to revisit the issue periodically.

\section{Inotropic infusion support}

Patients with end-stage HF refractory to standard treatment may be hospitalized or discharged home with inotropic intermittent or continuous-infusion support ${ }^{14,25}$ to improve dyspnea and increase exercise capacity. ${ }^{22}$ In a retrospective study of end-stage patients given continuous-infusion milrinone or dobutamine, the 6-month and 1-year survival rates were $58 \%$ and $44 \%$, respectively. ${ }^{128}$ Thus, a documented discussion between the patient, family, and health-care team should determine the patients' wishes about when not to increase the infusion rate and when to discontinue the inotropic therapy.

\section{Dyspnea}

Class I recommendations for the management of dyspnea include loop diuretics with or without thiazides, ${ }^{129}$ nitrates, ${ }^{120}$ or low-dose opioids. ${ }^{25,130,131}$ Class IIa recommendations include inotropes, aquapheresis (if diuretic resistant), ${ }^{132,133}$ walking aids, ${ }^{134}$ breathing ${ }^{134}$ and exercise training, ${ }^{135}$ and Hawthorn extract. ${ }^{136}$ A class IIB recommendation is oxygen (without hypoxia). ${ }^{137}$ 


\section{Pain}

Class I recommendations for the management of pain include opioids and bisphosphonates for bone pain, ${ }^{138}$ and nitrates, beta-blockers, calcium channel blockers, ranolazine, and coronary revascularization for anginal pain. ${ }^{138,139}$ Class IIb recommendations include acupuncture, ${ }^{140}$ exercise training, ${ }^{141}$ and music. ${ }^{142}$

\section{Fatigue}

There are no Class I recommendations for the treatment of fatigue. Class IIa recommendations include treatment of secondary causes such as anemia, infection, or sleep apnea; ${ }^{98,143}$ the use of stimulants; ${ }^{143}$ exercise training; ${ }^{144}$ and Hawthorne extract. ${ }^{137}$

\section{Depression}

The Class I recommendation for the treatment of depression is the use of selective serotonin reuptake inhibitors, serotonin-norepinephrine reuptake inhibitors, and tricyclic antidepressants. ${ }^{145}$ Class IIa recommendations include psychological interventions such as cognitive behavioral therapy, counseling, or supportive therapy ${ }^{146}$ while exercise ${ }^{147}$ is indicated as a Class IIb recommendation.

\section{Caregivers' needs}

Caregivers' needs relate to two primary domains of support: 1) support to enable them to provide care and 2) support for themselves. Caregivers' perspectives of key support needed during provision of EOL care at home describe 14 domains of needed support: 1) having a named support contact; 2) managing the patient's symptoms and medicines; ${ }^{9}$ 3) supporting with equipment knowledge; 4) providing personal care; 5) understanding the illness; 6) understanding the dying process; 7) talking with the patient about the illness; 8) supporting at the time of death; 9) providing caregiver respite support; addressing 10) physical health concerns, 11) financial issues, and 12) work issues; and providing 13) practical and 14) emotional support. ${ }^{148}$ Specifically, caregivers desired help communicating with the person for whom they cared, especially about dying and death ${ }^{47}$ Caregivers also described needs about how to cope with uncertainty, anxiety, and significant psychological morbidity. ${ }^{9}$ In addition, they voiced their own spiritual needs. ${ }^{9}$ Patients and caregivers were generally reluctant to raise spiritual issues, but many were able to talk about such needs. ${ }^{149}$

The brief Carer Support Needs Assessment Tool is a valid, evidence-based, 40 -item screening tool for use in practice to objectively determine the needs of $\mathrm{HF}$ caregivers that require further detailed assessment. ${ }^{148}$ The use of this tool may be helpful to identifying caregivers' needs.

\section{Conclusion}

Comprehensive HF care should integrate PC throughout the course of disease management and integrate $\mathrm{HC}$ at the EOL. Clinicians, in collaboration with a skilled multidisciplinary team, must advocate and provide for PC earlier rather than later in the HF disease trajectory addressing the humanistic and holistic needs of patients and families living and dying with HF. Care should be patient- and family-centered, and focused on planning for an uncertain future including completion of an advance directive, prevention and management of physical, psychosocial, and spiritual suffering; optimizing overall function and QOL; and achieving a satisfactory level of comfort.

Partnership with patients and families in managing their disease process is crucial. By empowering patients and families through the sharing of knowledge and support, effective communication and timely, honest feedback, patients and families are better able to maintain dignity, hope, and a level of optimism as they face the challenges ahead of them.

\section{Disclosure}

The authors report no conflicts of interest in this work.

\section{References}

1. Goodlin SJ, Hauptman PJ, Arnold R, et al. Consensus statement: palliative and supportive care in advanced heart failure. $J$ Card Fail. 2004;10(3):200-209

2. Formiga F, López-Soto A, Navarro M, Riera-Mestre A, Bosch X, Pujol R. Hospital deaths of people aged 90 and over: end-of-life palliative care management. Gerontology. 2008;54:148-152.

3. Formiga F, Chivite D, Ortega C, Casas S, Ramón JM, Pujol R. End-of-life preferences in elderly patients admitted for heart failure. QJM. 2004;97:803-808.

4. World Health Organization. WHO Definition of Palliative Care. Geneva: World Health Organization; 2009. Available from: http://www.who.int/ cancer/palliative/en/.

5. McCarthy M, Lay M, Addington-Hall J. Dying from heart disease. J R Coll Physicians Lond. 1996;30:325-328.

6. Murray SA, Worth A, Boyd K, et al. Patients', Carers' and Professionals' Experiences of Diagnosis, Treatment and End-of-Life Care in Heart Failure: A Prospective, Qualitative Interview Study. London: Department of Health/British Heart Foundation Heart Failure Research Initiative; 2007. Final report.

7. Murray SA, Sheikh A. Palliative care beyond cancer: care for all at the end of life. Br Med J. 2008;336:958-959.

8. Scottish Partnership for Palliative Care. Living and Dying with Advanced Heart Failure: A Palliative Care Approach. Scottish Partnership for Palliative Care; 2008. Available from: http://www.palliativecarescotland. org.uk.

9. Harding R, Selman L, Beynon T, et al. Meeting the communication and information needs of chronic heart failure patients. J Pain Symptom Manage. 2008;36:149-156. 
10. Bekelman DB, Hutt E, Masoudi FA, Kutner JS, Rumsfeld JS. Defining the role of palliative care in older adults with heart failure. Int J Cardiol. 2008:125:183-190.

11. Arnold JM, Liu P, Demers C, et al; Canadian Cardiovascular Society. Canadian Cardiovascular Society consensus conference recommendations on heart failure 2006: diagnosis and management. Can J Cardiol. 2006;22(1):23-45.

12. Brännström M, Forssell A, Pettersson B. Physicians' experiences of palliative care for heart failure patients. Eur J Cardiovasc Nurs. 2011;10(1):64-69.

13. Nordgren L, Sörensen S. Symptoms experienced in the last six months of life in patients with end-stage heart failure. Eur J Cardiovasc Nurs. 2003;2(3):213-217.

14. Adler ED, Goldfinger JZ, Kalman J, Park ME, Meier DE. Palliative care in the treatment of advanced heart failure. Circulation. 2009;120(25): 2597-2606.

15. Daveson BA, Harding R, Shipman C, et al. The real-world problem of care coordination: a longitudinal qualitative study with patients living with advanced progressive illness and their unpaid caregivers. PLoS One. 2014;9(5):1-12. e95523.

16. Howlett JG. Palliative care in heart failure: addressing the largest care gap. Curr Opin Cardiol. 2011;26:144-148.

17. Bakitas M, MacMartin M, Trzepkowski K, et al. Palliative care consultations for heart failure patients: how many, when, and why? J Card Fail. 2013;19:193-201.

18. Wotton K, Borbasi S, Redden M. When all else has failed: nurses' perception of factors influencing palliative care for patients with endstage heart failure. $J$ Cardiovasc Nurs. 2005;20(1):18-25.

19. Hupcey JE, Penrod J, Fogg J. Heart failure and palliative care: implications in practice. J Palliat Med. 2009;12(6):531-536.

20. National Consensus Project for Quality Palliative Care. National Consensus Project for Quality Palliative Care Home Page; 2013. Available from: http://www.nationalconsensusproject.org.

21. Ivany E, While A. Understanding the palliative care needs of heart failure patients. Br J Community Nurs. 2013;18(9):441-445.

22. Goodlin SJ. Palliative care in congestive heart failure. J Am Coll Cardiol. 2009;54:386-396.

23. O'Leary N, Murphy NF, O'Loughlin C, Tiernan E, McDonald K. A comparative study of the palliative care needs of heart failure and cancer patients. Eur J Heart Fail. 2009;11:406-412.

24. Boyd KJ, Worth A, Kendall M, et al. Making sure services deliver for people with advanced heart failure: a longitudinal qualitative study of patients, family carers, and health professionals. Palliat Med. 2009;23:767-776.

25. Stuart B. Palliative care and hospice in advanced heart failure. J Palliat Med. 2007;10(1):210-228.

26. Charnock LA. End of life care services for patients with heart failure. Nursing Standard. 2014;28(51):35-41.

27. Brown S, Macdonald S, May CR, Macleod U, Mair FS. Patient, carer and professional perspectives on barriers and facilitators to quality care in advanced heart failure. PLoS One. 2014;9(3):1-8. e93288.

28. Westlake C, Sethares K, Davidson P. How can health literacy influence outcomes in heart failure patients? Mechanisms and interventions. Curr Heart Fail Rep. 2013;10(3):232-243.

29. Pastor DK, Moore G. Uncertainties of the heart: palliative care and adult heart failure. Home Healthc Nurse. 2013;31(1):29-36.

30. Falk H, Ekman I, Anderson R, Fu M, Granger B. Older patients' experiences of heart failure-an integrative literature review. J Nurs Scholarsh. 2013;45(3):247-255.

31. Dev S, Abernethy AP, Rogers JG, O'Connor CM. Preferences of people with advanced heart failure - a structured narrative literature review to inform decision making in the palliative care setting. Am Heart J. 2012;164:313-319.

32. Pantilat SZ, O'Riordan DL, Dibble SL, Landefeld CS. Hospital-based palliative medicine consultation: a randomized controlled trial. Arch Intern Med. 2010;170(22):2038-2040.
33. Somogyi-Zalud E, Zhong Z, Lynn J, Hamel MB. Elderly persons' last six months of life: findings from the Hospitalized Elderly Longitudinal Project. J Am Geriatr Soc. 2000;48(Suppl 5):S131-S139.

34. ACC/AHA Practice Guidelines. ACC/AHA 2005 Guideline Update for the Diagnosis and Management of Chronic Heart Failure in the Adult. Circulation. 2005;112(12):e154-235. Epub 2005 Sep 13. Available from: http://circ.ahajournals.org/content/112/12/e154.full. Accessed November 19, 2014.

35. Stewart GC, Weintraub JR, Pratibhu PP, et al. Patient expectations from implantable defibrillators to prevent death in heart failure. J Card Fail. 2010;16(2):106-113.

36. Bekelman DB, Nowels CT, Retrum JH, et al. Giving voice to patients' and family caregivers' needs in chronic heart failure: implications for palliative care programs. J Palliat Med. 2011;14(12):1320.

37. Goldstein NE, Kalman J, Kutner JS, et al. A study to improve communication between clinicians and patients with advanced heart failure: method and challenges behind the Working to Improve diScussions about Defibrillator Management (WISDOM) trial. J Pain Symptom Manage. 2014;3:1-29.

38. MacIver J, Ross H. Quality of life and left ventricular assist device support. Circulation. 2012;126:866-874.

39. Wray J, Hallas CN, Banner NR. Quality of life and psychological well-being during and after left ventricular assist device support. Clin Transplant. 2007;21:622-627.

40. O'Neill BJ, Kazer MW. Destination to nowhere: a new look at aggressive treatment for heart failure - a case study. Crit Care Nurse. 2014;34(2):47-54.

41. Davidson JE. Family-centered care: meeting the needs of patients' families and helping families adapt to critical illness. Crit Care Nurse. 2009;29(3):28-34.

42. Allen LA, Yager JE, Funk MJ. Discordance between patient-predicted and model-predicted life expectancy among ambulatory patients with heart failure. JAMA. 2008;299:2533-2542.

43. Sobanski P, Jaarsma T, Krajnik M. End of life matters in chronic heart failure patients. Curr Opin Support Palliat Care. 2014;8(4):364-370.

44. Goodlin SJ, Cassell E. Coping with patient's deaths. In: Beattie J, Goodlin S, editors. Supportive Care in Heart Failure. Oxford: Oxford University Press; 2008:477-482.

45. Goodlin SJ, Quill TE, Arnold RM. Communication and decisionmaking about prognosis in heart failure care. J Card Fail. 2008;14(2): 106-113.

46. Fitzsimmons D, Mullan D, Wilson JS. The challenge of patients' unmet palliative care needs in the final stages of chronic illness. Palliat Med. 2007;21:313-322.

47. Moser DK, Dracup KA, Marsden C. Needs of recovering cardiac patients and their spouses: compared views. Int J Nurs Stud. 1993;30: $105-114$.

48. HagenhoffBD, Feutz C, Conn VS, Safehorn KK, Moranville-Hunziker M. Patient education needs as reported by congestive heart failure patients and their nurses. J Adv Nurs. 1994;19:685-690.

49. Dracup K, Baker DW, Dunbar SB, Dacey RA, Brooks NH, Johnson JC. Management of heart failure: II. Counseling, education, and lifestyle modifications. JAMA. 1994;272:1442-1446.

50. Dracup K, Moser DK, Guzy PM, Taylor SE, Marsden C. Is cardiopulmonary resuscitation training deleterious for family members of cardiac patients? Am J Public Health. 1994;84:116-118.

51. Dracup K, Heaney DM, Taylor SE, Guzy PM, Breu C. Can family members of high-risk cardiac patients learn cardiopulmonary resuscitation? Arch Intern Med. 1989;149:61-64.

52. Waterworth S, Jorgensen D. It's not just about heart failure - voices of older people in transition to dependence and death. Health Soc Care Community. 2010;18(2):199-207.

53. Buck HG, Zambroski CH. Upstreaming palliative care for patients with heart failure. J Cardiovasc Nurs. 2012;27(2):147-153.

54. Campbell ML, Frank RR. Experience with an end-of-life practice at a university hospital. Crit Care Med. 1997;25:197-202. 
55. Evangelista LS, Lombardo D, Malik S, Ballard-Hernandez J, Motie M, Liao S. Examining the effects of an outpatient palliative care consultation on symptom burden, depression, and quality of life in patients with symptomatic heart failure. J Card Fail. 2012;18(12): 894-899.

56. Dougherty CM, Pyper GP, Au DH, Levy WC, Sullivan MD. Drifting in a shrinking future living with advanced heart failure. $J$ Cardiovasc Nurs. 2007;22(6):480-487.

57. Willems DL, Hak A, Visser FC, Cornel J, van der Wal G. Patient work in end-stage heart failure: a prospective longitudinal multiple case study. Palliat Med. 2006;20:25-33.

58. Hagglund L, Boman K, Lundman B. The experience of fatigue among elderly women with chronic heart failure. Eur J Cardiovasc Nurs. 2008;7(4):290-295.

59. Retrum JH, Nowels CT, Bekelman DB. Patient and caregiver congruence: the importance of dyads in heart failure care. J Cardiovasc Nurs. 2013;28(2):129-136.

60. Cleland JG, Tendera M, Adamus J, et al. The perindopril in elderly people with chronic heart failure (PEP-CHF) study. Eur Heart $J$. 2006;27:2338-2345.

61. Captopril Multicenter Research Group. A placebo-controlled trial of captopril in refractory chronic congestive heart failure. $J$ Am Coll Cardiol. 1983;2:755-763.

62. Notarius CF, Morris B, Floras JS. Caffeine prolongs exercise duration in heart failure. J Card Fail. 2006;12:220-226.

63. Garg R, Yusuf S. Overview of randomized trials of angiotensinconverting enzyme inhibitors on mortality and morbidity in patients with heart failure. Collaborative Group on ACE Inhibitor Trials. JAMA. 1995;273:1450-1456.

64. Mansfield DR, Gollogly NC, Kaye DM. Controlled trial of continuous positive airway pressure in obstructive sleep apnea and heart failure. Am J Respir Crit Care Med. 2004;169:361-366.

65. Bayliss J, Norell M, Canepa-Anson R, Sutton G, Poole-Wilson P. Untreated heart failure: clinical and neuroendocrine effects of introducing diuretics. Br Heart J. 1987;57:17-22.

66. Colin Ramirez E, Castillo Martinez L, Orea Tejeda A. Effects of a nutritional intervention on body composition, clinical status and quality of life in patients with heart failure. Nutrition. 2004;20:890-895.

67. Dracup K, Westlake C, Erickson VS, Moser DK, Caldwell ML, Hamilton MA. Perceived control reduces emotional stress in patients with heart failure. J Heart Lung Transplant. 2003;22:90-93.

68. Yeh GY, Wood MJ, Lorell BH. Effects of tai chi mind-body movement therapy on functional status and exercise capacity in patients with chronic heart failure: a randomized controlled trial. Am J Med 2004;117:541-548.

69. Bartlo P. Evidence-based application of aerobic and resistance training in patients with congestive heart failure. J Cardiopulm Rehabil Prev. 2007;27:368-375.

70. Chiappa GR, Roseguini BT, Vieira PJ. Inspiratory muscle training improves blood flow to resting and exercising limbs in patients with chronic heart failure. J Am Coll Cardiol. 2008;51:1663-1671.

71. Laoutaris I, Dritsas A, Brown MD, Manginas A, Alivizatos PA, Cokkinos DV. Inspiratory muscle training using an incremental endurance test alleviates dyspnea and improves functional status in patients with chronic heart failure. Eur J Cardiovasc Prev Rehabil. 2004;11: 489-496.

72. Mancini DM, Henson D, La Manca J, Donchez L, Levine S. Benefit of selective respiratory muscle training on exercise capacity in patients with chronic congestive heart failure. Circulation. 1995;91: 320-329.

73. Mancini DM, Katz SD, Lang CC. Effect of erythropoietin on exercise capacity in patients with moderate to severe chronic heart failure. Circulation. 2003;107:294-299.

74. Freemantle N, Tharmanathan P, Calvert MJ. Cardiac resynchronisation for patients with heart failure due to left ventricular systolic dysfunction: a systematic review and meta-analysis. Eur J Heart Fail. 2006;8: 433-440.
75. Rose EA, Gelijns AC, Moskowitz AJ. Randomized evaluation of mechanical assistance for the treatment of congestive heart failure (REMATCH) study group long-term use of a left ventricular assistance for end-stage heart failure. $N$ Engl J Med. 2001;345: $1435-1443$.

76. Beniaminovitz A, Lang CC, LaManca J, Mancini DM. Selective lowlevel leg muscle training alleviates dyspnea in patients with heart failure. J Am Coll Cardiol. 2002;40:1602-1608.

77. Pitt B, Zannad F, Remme WJ. The effect of spironolactone on morbidity and mortality in patients with severe heart failure. $N$ Engl $\mathrm{J}$ Med. 1999;341:709-717.

78. Binanay C, Califf RM, Hasselblad V. ESCAPE investigators and ESCAPE study coordinators evaluation study of congestive heart failure and pulmonary artery catheterization effectiveness: the ESCAPE trial. JAMA. 2005;294:1625-1633.

79. Krantz MJ, Martin J, Stimmel B, Mehta D, Haigney MC. QTc interval screening in methadone treatment. Ann Intern Med. 2009;150: 387-395.

80. Chua TP, Harrington D, Ponikowski P, Webb-Peploe K, Poole-Wilson PA, Coats AJ. Effects of dihydrocodeine on chemosensitivity and exercise tolerance in patients with chronic heart failure. $\mathrm{J} \mathrm{Am} \mathrm{Coll} \mathrm{Cardiol.}$ 1997;29:147-152.

81. Johnson MJ, McDonagh TA, Harkness A, McKay SE, Dargie HJ. Morphine for the relief of breathlessness in patients with chronic heart failure - a pilot study. Eur J Heart Fail. 2002;4:753-756.

82. Williams SG, Wright DJ, Marshall P. Safety and potential benefits of low dose diamorphine during exercise in patients with chronic heart failure. Heart. 2003;89:1085-1086.

83. Krum H, Sackner-Bernstein JD, Goldsmith RL. Double-blind, placebo-controlled study of the long-term efficacy of carvedilol in patients with severe chronic heart failure. Circulation. 1995;92: 1499-1506.

84. Packer M, Fowler MB, Roecker EB. Effect of carvedilol on the morbidity of patients with severe chronic heart failure: results of the carvedilol prospective randomized cumulative survival (COPERNICUS) study Circulation. 2002;106:2194-2199.

85. Broström A, Hubbert L, Jakobsson P, Johansson P, Fridlund B, Dahlström $\mathrm{U}$. Effects of long-term nocturnal oxygen treatment in patients with severe heart failure. J Cardiovasc Nurs. 2005;20:385-396.

86. Cohn JN, Goldstein SO, Greenberg BH. A dose-dependent increase in mortality with vesnarinone among patients with severe heart failure. Vesnarinone Trial Investigators. N Engl J Med. 1998;339: 1810-1816.

87. Hershberger RE, Nauman D, Walker TL, Dutton D, Burgess D. Care processes and clinical outcomes of continuous outpatient support with inotropes (COSI) in patients with refractory endstage heart failure. J Card Fail. 2003;9:180-187.

88. Kaneko Y, Floras JS, Usui K. Cardiovascular effects of continuous positive airway pressure in patients with heart failure and obstructive sleep apnea. N Engl J Med. 2003;348:1233-1241.

89. Yamamoto U, Mohri M, Shimada K. Six-month aerobic exercise training ameliorates central sleep apnea in patients with chronic heart failure. $J$ Card Fail. 2007;13:825-829.

90. Evangelista LS, Dracup K, Doering L, Westlake C, Fonarow GC, Hamilton M. Emotional well-being of heart failure patients and their caregivers. J Card Fail. 2002;8:300-305.

91. Sullivan MJ, Wood L, Terry J. The support, education and research in chronic heart failure (SEARCH) study: a mindfulness-based psychoeducational intervention improves depression and clinical symptoms in patients with chronic heart failure. Am Heart J. 2009;157: 84-90.

92. Jacob S, Spinler SA. Hyponatremia associated with selective serotoninreuptake inhibitors in older adults. Ann Pharmacother. 2006;40: $1618-1622$.

93. Horne G, Payne S. Removing the boundaries: palliative care for patients with heart failure. Palliat Med. 2004;18:291-296. 
94. Westlake C, Dracup K. Role of spirituality in adjustment of patients with advanced heart failure. Prog Cardiovasc Nurs. 2001;16(Summer 3): 119-125.

95. Strachan P, Ross H, Rocker G, Dodek P, Heyland D. Mind the gap: opportunities for improving end-of-life care for patients with advanced heart failure. Can J Cardiol. 2009;25(11):635-640.

96. Waller A, Girgis A, Davidson PM, et al. Facilitating needs-based support and palliative care for people with chronic heart failure: preliminary evidence for the acceptability, inter-rater reliability, and validity of a needs assessment tool. J Pain Symptom Manage. 2013;45(5):912-925.

97. Ross L, Austin J. Spiritual needs and spiritual support preferences of people with end-stage heart failure and their carers: implications for nurse managers. J Nurs Manag. 2013;7:1-9.

98. Ponikowski P, Anker SD, Chua TP, et al. Oscillatory breathing patterns during wakefulness in patients with chronic heart failure: clinical implications and role of augmented peripheral chemosensitivity. Circulation. 1999;100:2418-2424.

99. Hauptman PJ, Havranek EP. Integrating palliative care into heart failure care. Arch Intern Med. 2005;165:374-378.

100. Fox E, Landrum-Mcniff K, Zhong Z, Dawson NV, Wu AW, Lynn J. Evaluation of prognostic criteria for determining hospice eligibility in patients with advanced lung, heart, or liver disease: SUPPORT Investigators: study to understand prognoses and preferences for outcomes and risks of treatments. JAMA. 1999;282:1638-1645.

101. Teno JM, Clarridge BR, Casey V, et al. Family perspectives on endof-life care at the last place of care. JAMA. 2004;291:88-93.

102. Davis MP, Albert NM, Young JB. Palliation of heart failure. Am J Hosp Palliat Care. 2005;22:211-222.

103. Gott M, Barnes S, Parker C, Payne S, Seamark D, Small N. Dying trajectories in heart failure. Palliat Med. 2007;21:95-99.

104. Huynh BC, Rovner A, Rich MW. Identification of older patients with heart failure who may be candidates for hospice care: development of a simple four-item risk score. J Am Geriatr Soc. 2008;56: 1111-1115.

105. Levenson JW, McCarthy EP, Lynn J, Davis RB, Phillips RS. The last six months of life for patients with congestive heart failure. J Am Geriatr Soc. 2000;48:S101-S109.

106. Casarett DJ, Quill TE. "I'm not ready for hospice": strategies for timely and effective hospice discussions. Ann Intern Med. 2007;146:443-449.

107. Rohde LE, Goldraich L, Polanczyk Cam Borges AP, et al. A simple clinically based predictive rule for heart failure in-hospital mortality. J Card Fail. 2006;12(8):587-593.

108. Abraham W, Fonarow G, Young J, et al. Predictors of in-hospital mortality in patients hospitalized for heart failure: insights from the Organized Program to Initiate Lifesaving Treatment in Hospitalized Patients with Heart Failure (OPTIMIZE-HF). Journal Of The American College Of Cardiology. 2008;52(5):347-356.

109. Bittner V, Weiner DH, Yusuf S, et al; SOLVD Investigators. Prediction of mortality and morbidity with a 6-minute walk test in patients with left ventricular dysfunction. JAMA. 1993;270:1702-1707.

110. Doust JA, Pietrzak E, Dobson A, Glasziou P. How well does B-type natriuretic peptide predict death and cardiac events in patients with heart failure: systematic review. BMJ. 2005;330:625.

111. Smith GL, Vaccarino V, Kosiborod M, et al. Worsening renal function: what is a clinically meaningful change in creatinine during hospitalization with heart failure? J Card Fail. 2003;9:13-25.

112. Aaronson KD, Schwartz JS, Chen TM, Wong KL, Goin JE, Mancini DM. Development and prospective validation of a clinical index to predict survival in ambulatory patients referred for cardiac transplant evaluation. Circulation. 1997;95: 2660-2667.

113. Zugck C, Kruger C, Kell R, et al. Risk stratification in middle-aged patients with congestive heart failure: prospective comparison of the Heart Failure Survival Score (HFSS) and a simplified two-variable model. Eur J Heart Fail. 2001;3:577-585.
114. Lee DS, Austin PC, Rouleau JL, Liu PP, Naimark D, Tu JV. Predicting mortality among patients hospitalized for heart failure: derivation and validation of a clinical model. JAMA. 2003;290:2581-2587.

115. Pocock SJ, Ariti CA, McMurray JV, et al; on behalf of the MetaAnalysis Global Group in Chronic Heart Failure (MAGGIC). Predicting survival in heart failure: a risk score based on 39372 patients from 30 studies. Eur Heart J. 2013;34(19):1404-1413.

116. Brophy JM, Dagenais GR, McSherry F, Williford W, Yusuf S. A multivariate model for predicting mortality in patients with heart failure and systolic dysfunction. Am J Med. 2004;116:300-304.

117. Levy WC, Mozaffarian D, Linker DT, et al. The Seattle Heart Failure Model: prediction of survival in heart failure. Circulation. 2006;113:1424-1433.

118. Stempfle HU, Alt A, Stief J, Siebert U. The Munich score: a clinical index to predict survival in ambulatory patients with chronic heart failure in the era of new medical therapies. J Heart Lung Transplant. 2008;27:222-228.

119. Lupón J, de Antonio M, Vila J, et al. Development of a novel heart failure risk tool: the Barcelona bio-heart failure risk calculator (BCN Bio-HF Calculator). PLoS One. 2014;9(1):e85466.

120. Anderson F, Downing G, Hill J, Casorso L, Lerch N. Palliative performance scale: a new tool. J Palliat Care. 1996;12(1):5-11.

121. Ezekowitz JA, Thai V, Hodenfield TS, Sanderson L, Cujec B. The correlation of Standard heart failure assessment and palliative care questionnaires in a multidisciplinary heart failure clinic. J Pain Symptom Manage. 2011;42(379e):387.

122. Yamokoski LM, Hasselblad V, Moser DK. Prediction of rehospitalization and death in severe heart failure by physicians and nurses of the ESCAPE trial. J Cardiac Fail. 2007;13:8-13.

123. Kaasalainen S, Strachan PH, Heckman GA, et al. Living and dying with heart failure in long-term care: experiences of residents and their family members. Int J Palliat Nurs. 2013;19(4):435-482.

124. Singer PA, Martin DK, Kelner M. Quality end-of-life care: patients' perspectives. JAMA. 1999;281(2):163-168.

125. Schockett ER, Teno JM, Miller SC, Stuart B. Late referral to hospice and bereaved family member perception of quality of end-of-life care. J Pain Symptom Manage. 2005;30:400-407.

126. Goldstein N, Carlson M, Livote E, Kutner JS. Brief communication: management of implantable cardioverter-defibrillators in hospice: a nationwide survey. Ann Intern Med. 2010;152(5):296-299.

127. Whittingham K, Hodgson LJ. The complexities of caring for a patient with an ICD in end-stage heart failure. Br J Cardiac Nurs. 2010;5(12):568-575.

128. Fonarow GC, Yancy CW, Hernandez AF, Peterson ED, Spertus JA, Heidenreich PA. Potential impact of optimal implementation of evidence-based heart failure therapies on mortality. Am Heart J. 2011;161(6):1024-1030.

129. Faris R, Flather MD, Purcell H, Poole-Wilson PA, Coats AJ. Diuretics for heart failure. Cochrane Database Syst Rev. 2006:CD003838.

130. Jennings AL, Davies AN, Higgins JP, Gibbs JS, Broadley KE. A systematic review of the use of opioids in the management of dyspnoea. Thorax. 2002;57:939-944.

131. Abernethy AP, Currow DC, Frith P, Fazekas BS, McHugh A, Bui C. Randomized, double blind, placebo controlled crossover trial of sustained release morphine for the management of refractory dyspnoea. BMJ. 2003;327:523-528.

132. Packer M. Effect of vasodilator and inotropic drugs on clinical symptoms and long-term survival in chronic congestive heart failure. Eur Heart J. 1988;9(Suppl H):105-108.

133. Costanzo MR, Guglin ME, Saltzberg MT, et al; UNLOAD Trial Investigators. Ultrafiltration versus intravenous diuretics for patients hospitalized for acute decompensated heart failure. J Am Coll Cardiol. 2007;49:675-683.

134. Bausewein C, Booth S, Gysels M, Higginson I. Non-pharmacological interventions for breathlessness in advanced stages of malignant and non-malignant diseases. Cochrane Database Syst Rev. 2008: CD005623. 
135. Pozehl B, Duncan K, Hertzog M. The effects of exercise training on fatigue and dyspnea in heart failure. Eur J Cardiovasc Nurs. 2008;7: $127-132$.

136. Pittler MH, Guo R, Ernst E. Hawthorn extract for treating chronic heart failure. Cochrane Database Syst Rev. 2008:CD005312.

137. Booth S, Anderson H, Swannick M, Wade R, Kite S, Johnson M. The use of oxygen in the palliation of breathlessness: a report of the expert working group of the Scientific Committee of the Association of Palliative Medicine. Respir Med. 2004;98:66-77.

138. Qaseem A, Snow V, Shekelle P, et al; Clinical efficacy assessment subcommittee of the American college of physicians. Evidence-based interventions to improve the palliative care of pain, dyspnea, and depression at the end of life: a clinical practice guideline from the American College of Physicians. Ann Intern Med. 2008;148:141-146.

139. Fraker TD, Fihn SD, Gibbons RJ, et al. 2007 Chronic angina focused update of the ACC/AHA 2002 guidelines for the management of patients with chronic stable angina: a report of the American College of Cardiology/American Heart Association Task Force on Practice Guidelines Writing Group to develop the focused update of the 2002 guidelines for the management of patients with chronic stable angina. J Am Coll Cardiol. 2007;50:2264-2274.

140. Lee H, Schmidt K, Ernst E. Acupuncture for the relief of cancer-related pain: a systematic review. Eur J Pain. 2005;9:437-444.

141. Knols R, Aaronson NK, Uebelhart D, Fransen J, Aufdemkampe G. Physical exercise in cancer patients during and after medical treatment: a systematic review of randomized and controlled clinical trials. J Clin Oncol. 2005;23:3830-3842.

142. Cepeda MS, Carr DB, Lau J, Alvarez H. Music for pain relief. Cochrane Database Syst Rev. 2006:CD004843.
143. Harris JD. Fatigue in chronically ill patients. Curr Opin Support Palliat Care. 2008;2:180-186; Radbruch L, Strasser F, Elsner F, et al; Research Steering Committee of the European Association for Palliative Care (EAPC). Fatigue in palliative care patients: an EAPC approach. Palliat Med. 2008;22:13-32.

144. Radbruch L, Strasser F, Elsner F, et al; Research Steering Committee of the European Association for Palliative Care (EAPC). Fatigue in palliative care patients: an EAPC approach. Palliat Med. 2008;22:13-32.

145. Rutledge T, Reis VA, Linke SE, Greenberg BH, Mills PJ. Depression in heart failure: a meta-analytic review of prevalence, intervention effects, and associations with clinical outcomes. J Am Coll Cardiol. 2006;48:1527-1537.

146. Lane DA, Chong AY, Lip GY. Psychological interventions for depression in heart failure. Cochrane Database Syst Rev. 2005: CD003329.

147. Ströhle A. Physical activity, exercise, depression and anxiety disorders J Neural Transm. 2009;116:777-784.

148. Ewing G, Grande G. Development of a Carer Support Needs Assessment Tool (CSNAT) for end-of-life care practice at home: a qualitative study. Palliat Med. 2012;27(3):244-256.

149. Murray SA, Kendall M, Boyd K, Benton TF. Exploring the spiritual needs of people dying of lung cancer or heart failure: a prospective qualitative interview study of patients and their carers. Palliat Med. 2004;18(1):39-45.

150. Galbraith S, Fagan P, Perkins P, Lynch A, Booth S. Does the use of a handheld fan improve chronic dyspnea? A randomized, controlled, crossover trial. Journal Of Pain And Symptom Management 2010;39(5):831-838
Nursing: Research and Reviews

\section{Publish your work in this journal}

Nursing: Research and Reviews is an international, peer-reviewed, open access journal publishing original research, reports, reviews and commentaries on all aspects of nursing and patient care. These include patient education and counselling, ethics, management and organizational issues, diagnostics and prescribing, economics and

\section{Dovepress}

resource management, health outcomes, and improving patient safety in all settings. The manuscript management system is completely online and includes a very quick and fair peer-review system. Visit http://www.dovepress.com/testimonials.php to read real quotes from published authors. 